\title{
DINÂMICAS LÚDICAS PARA TRABALHAR O SENTIMENTO DE PERTENCIMENTO DO SER HUMANO À NATUREZA, NA ESCOLA SALOMÉ DE CARVALHO, MARABÁ (PA)
}

\author{
Edléia A. Ferreira de Sousa ${ }^{1}$ \\ Maria do Carmo Vieira Filha ${ }^{2}$ \\ Mário Médice Costa Barbosa ${ }^{3}$
}

Resumo: Este trabalho refere-se a uma pesquisa-participante realizada pela Comissão de Meio Ambiente do IFPA, conjuntamente com discentes do curso de Controle Ambiental, Campus Marabá Industrial, cujo tema central foi a presentar aos discentes do 9ำ ano da Escola Municipal Salomé de Carvalho, o seu pertencimento à natureza. $\mathrm{O}$ caminho trilhado para a pesquisa foi a partir de um questionário diagnóstico acerca da temática ambiental e após a análise dos dados foi desenvolvida uma oficina centrada no pertencimento do ser humano à natureza. Nessa oficina foram trabalhadas quatro dinâmicas lúdicas, com objetivos diferenciados, mas que convergiam para o objetivo proposto.

Palavras-chave: Pesquisa-Participante; Educação; Pertencimento; Meio Ambiente. 


\section{Introdução}

$\mathrm{Na}$ sociedade hodierna, permeada de conflitos socioambientais, culturais, políticos e econômicos é comum assinalar que a Educação Ambiental (EA) é uma ferramenta capaz de realizar intervenções positivas no intuito de promover mudanças de comportamento e atitudes aos indivíduos que integram essa sociedade.

E esse é um fato verídico, confirmado por inúmeras atividades sobre Educação Ambiental desenvolvidas em instituições formais de educação ou não formais, que auxiliam na resolução de problemas e que muito interferem na qualidade de vida das pessoas dessas localidades (GUIMARÃES, 2011).

Assim como as políticas públicas desenvolvidas através da Lei 9795/99 que dispõe sobre a Política Nacional de Educação Ambiental, que em seu Art. 1o afirma:

Entendem-se por Educação Ambiental os processos por meio dos quais o indivíduo e a coletividade constroem valores sociais, conhecimentos, habilidades, atitudes e competências voltadas para a conservação do meio ambiente, bem de uso comum do povo, essencial à sadia qualidade de vida e sua sustentabilidade (BRASIL, 1999).

Também com outras disposições legais como a Lei 6938/81, que trata da Política Nacional do Meio Ambiente e tem como princípio, no inciso X: "Educação Ambiental a todos os níveis de ensino, inclusive a educação da comunidade, objetivando capacitá-la para participação ativa na defesa do meio ambiente" (BRASIL, 1981).

Dessa forma, a EA é reconhecida como aquela, que possibilita ao indivíduo a transformar-se em sujeito ativo que percebe e influencia o meio social, cultural, político, econômico e físico que está envolvido, ao que Carvalho (2016, p. 67), afirma serem "facetas variadas" do sujeito ecológico, pois este "agrega uma série de traços, valores e crenças" que "operam uma orientação de vida, expressando-se de diversas maneiras por meio das características pessoais e coletivas de indivíduos e grupos em suas condições sócio históricas de existência".

E de forma a auxiliar na aquisição de informações e conhecimentos, que possam fortalecer, modificar ou ressignificar essas crenças, traços e valores, tem-se a EA crítica que segundo Sauvé (2005, p. 31), vem "[...] para a resolução de problemas locais e para o desenvolvimento local. Insiste na contextualização dos temas tratados e na importância do diálogo dos saberes: saberes científicos formais, saberes cotidianos, saberes de experiência, saberes tradicionais, etc."

Assim, será possível confrontar as ideias e os diferentes saberes entre se, utilizando a criticidade para que a ação seja constituída de uma perspectiva 
crítica e sistêmica, possibilitando identificar e salientar as relações entre os elementos físicos, biofísicos e sociais.

Ainda sendo pertinente afirmar uma EA emancipatória, a qual afirma Malvezzi (2013), ser aquela que anseia por uma nova organização de sociedade, na qual os seus inúmeros e diferenciados sujeitos possam exercer efetivamente sua participação ativa na resolução dos conflitos que surgem constantemente.

Portanto, em um país de tamanho continental como o Brasil, os conflitos existentes são inúmeros e de diferentes matizes e assolam todas as classes sociais e culturais, sendo pertinentes ações realizadas por variados grupos societários, que visam disseminar a EA de forma a contribuir com a melhoria da qualidade de vida dos cidadãos e consequentemente efetivar o respeito ao meio ambiente físico e social que estão inseridos.

E seguindo essa linha de raciocínio, a Comissão de Meio Ambiente do Instituto Federal de Educação, Ciência e Tecnologia do Pará (IFPA), Campus Marabá Industrial, desenvolve pesquisas que possam fomentar nos discentes e docentes o desejo de cada vez mais participarem ativamente das decisões relativas à comunidade interna e externa ao Campus, contribuindo para o empoderamento desses sujeitos.

Por isso, foram desenvolvidas ações pertinentes ao tema Educação Ambiental crítica com discentes e docentes desse Campus, o que frutificou posteriormente em intervenções na comunidade externa, tendo como sujeitos interventivos os próprios discentes.

Assim sendo, esse trabalho refere-se ao desenvolvimento de uma pesquisa participante, composta de ações específicas e pontuais, cujo objetivo fora auxiliar na retomada da ideia do pertencimento do ser humano à natureza, em contrário à dicotomia ser humano-natureza, pois esse foi um tópico importante sinalizado em uma diagnose realizada na Escola Municipal de Ensino Fundamental Salomé de Carvalho, com discentes de três turmas de nono ano, acerca do entendimento dos mesmos no tocante aos conceitos de meio ambiente, Educação Ambiental e sustentabilidade.

E dentre esses tópicos pesquisados foi decidido em discussões reflexivas que as atividades deveriam focar nessa dicotomia ser humanonatureza, que tomou corpo a partir da Revolução Industrial e serviu de contributo para a formação das bases sociais hodiernas, na qual a natureza é coisificada, suscitando a ideia de que o ser humano pode e deve usufruir dela (GONÇALVES, 2011).

Assim, após a análise das respostas do questionário diagnóstico, foram planejadas ações, que seriam desenvolvidas por discentes que participam de projetos de EA no Campus e aceitaram o desafio de levar seu aprendizado ao outros discentes, pois Freire (1996, p. 21), afirma que "ensinar não é transferir conhecimento" e que a teoria tem que ser tão palpável que quase se confunda com a prática, por isso a necessidade de promover uma atividade que o próprio 
educando, após vivenciar a teoria a colocasse em prática, auxiliando o crescimento de outros indivíduos.

Então, investido desses propósitos e no intuito de consolidá-los, o primeiro passo para a realização dessa atividade foi a reunião da representante da Comissão de Meio Ambiente com a gestão da escola alvo para formar a parceira no desenvolvimento da pesquisa e essa ação foi seguida pela aplicação do questionário diagnóstico embasado na temática escolhida.

Após a tabulação dos dados, apresentação ao corpo docente da escola parceira, a gestão abriu as portas da instituição confiando no trabalho que seria articulado, sendo que esse se desenvolveu através de uma oficina composta de roda de conversa e dinâmicas, que possibilitaram a interação entre os discentes do IFPA e da escola Salomé de Carvalho, além de proporcionar momentos lúdicos que propiciaram uma participação efetiva e descontraída de todos.

E essa característica de lúdico foi escolhida devido ao fato de lidarmos com adolescentes, que na atual conjuntura tecnológica estão constantemente imersos em aplicativos, redes sociais, de forma que o lúdico das dinâmicas seria um modo de chamar a atenção, pois afirma Huizinga (1980), que esse é pertencente à natureza, estando presente nas sociedades em todos os tempos, pois ultrapassa o físico e vai de encontro a uma realidade metafórica.

Além de que ocorre nesse momento o respeito aos variados saberes, ocorrendo uma exposição de diversos olhares sobre um mesmo tema e quando direcionada para vertente crítica da EA, alcança o objetivo de contextualização reflexiva, que empodera o adolescente como construtor de seu caminho na vida em sociedade.

\section{Trilhar o caminho é praticar a teoria, vencendo medos e colhendo vitórias}

A Comissão de Meio Ambiente do Campus Marabá Industrial, através da parceria com a Escola Municipal de Ensino Fundamental Salomé de Carvalho, desenvolveu uma pesquisa diagnóstica com os alunos do non ano, acerca da compreensão dos mesmos sobre as temáticas meio ambiente, Educação Ambiental e sustentabilidade.

Para tal fim, foram aplicados questionários diagnósticos a todos os alunos das três turmas do nono ano da escola alvo, tendo no total a participação de 95 indivíduos.

Os questionários foram compostos por questionamentos simples e diretos acerca da temática pesquisada e cujas respostas foram categorizadas para uma melhor análise das mesmas, de forma a permitir ações pontuais e exequíveis. 
Após a análise foram planejadas ações para auxiliar os participantes a ressignificarem seus conceitos acerca do seu pertencimento à natureza, meio ambiente, Educação Ambiental e sustentabilidade.

E uma metodologia que pode ser utilizada para desenvolver essa leitura crítica de mundo são as oficinas, que segundo Candau (2013), constitui um espaço de construção coletiva do conhecimento, de análise da realidade, de confronto e troca de experiências.

A escolha baseada na metodologia de oficina abarca a construção coletiva do saber, através de interação e trocas de saberes, devido basear-se na dialética em relação ao educador e educando (CANDAU, 2013). Portanto, a construção do saber de cada educando será própria, segundo sua compreensão de natureza e como essa compreensão irá fornecer subsídios para desenvolver na prática o saber.

A intenção é que seja uma dinâmica participativa e reflexiva que fomente a teoria-prática, de forma a consubstanciar no educando a vontade de ir mais além ao seu próprio mundo, depois de conseguir alinhar seu olhar ao derredor e perceber-se como sujeito no seu mundo (CARVALHO, 2016).

Assim sendo, a oficina foi desenvolvida por seis alunos do curso Técnico Integrado ao Médio de Controle Ambiental, que participam de atividades da Comissão de Meio Ambiente do Campus Marabá Industrial.

A mesma compõe-se de rodas de conversa e dinâmicas lúdicas, pois conforme Huizinga (1980), o lúdico é fator pertencente à cultura de todos os povos e é também encontrado em todas as organizações sociais, haja vista que ultrapassa os limites físicos da realidade, transcendo e criando metaforicamente.

As dinâmicas utilizadas na oficina foram quatro, das quais três foram retiradas da obra de Dias (2013), sendo que a primeira objetivava trabalhar a ideia de pertencimento do ser humano ao meio natural através do conhecimento de como as leis naturais influenciam a vida do ser humano.

A segunda também sobre as leis naturais intentando realizar uma conexão entre o sentir as vibrações do impacto dos passos e o perceber a condição humana à ação da gravidade.

A terceira, intitulada "sentindo a natureza em mim", para identificar a reação do ser humano quando privado do sentido da visão e necessitando de outro ser para dirigir seus passos, em um ambiente diferente do que está acostumado a viver, de forma a identificar em si a complexidade da natureza.

E para encerrar as dinâmicas, a atividade dinâmica dos sistemas cujo objetivo foi demonstrar as interdependências que existe entre os variados sistemas aos quais os seres humanos estão vinculados.

Então, como forma de avaliação dos momentos vivenciados pelos discentes da escola municipal foram aplicadas fichas avaliativas, que continham itens simples e de fácil compreensão. No entanto, esse momento 
não foi obrigatório, apenas para aqueles que se sentissem seguros para realizar.

\section{No caminho entre a teoria e a prática existe uma parada para a reflexão}

O processo de reflexão entre a teoria e prática é pertinente quando os participantes estão propensos a aprender constantemente e não se fecham às suas ideias como findas e únicas válidas.

Assim, para que se pudesse desenvolver um trabalho coeso, sério e útil a avaliação foi uma constante em todos os momentos dessa pesquisaparticipante, pois seria um modo de intervir de forma segura no meio social pesquisado e também de ofertar conhecimento aos pesquisadores.

A análise das respostas dos discentes acerca dos conceitos abordados é apresentada na Figura 1, iniciando com o conceito de meio ambiente, no qual 93\% relacionaram meio ambiente aos rios, florestas e ar, ou seja, a dicotomia ser humano-natureza está presente de forma contundente, pois é excluída toda e qualquer relação social.

O ser humano está fora do ambiente e essa ausência pode interferir significativamente nas atitudes e comportamentos desses indivíduos quando se trata de reflexões críticas acerca das causas dos conflitos socioambientais, pois se ele não faz parte da natureza, o que acontece com ela ou a partir dela pode the ser indiferente (REIGOTA, 2014).

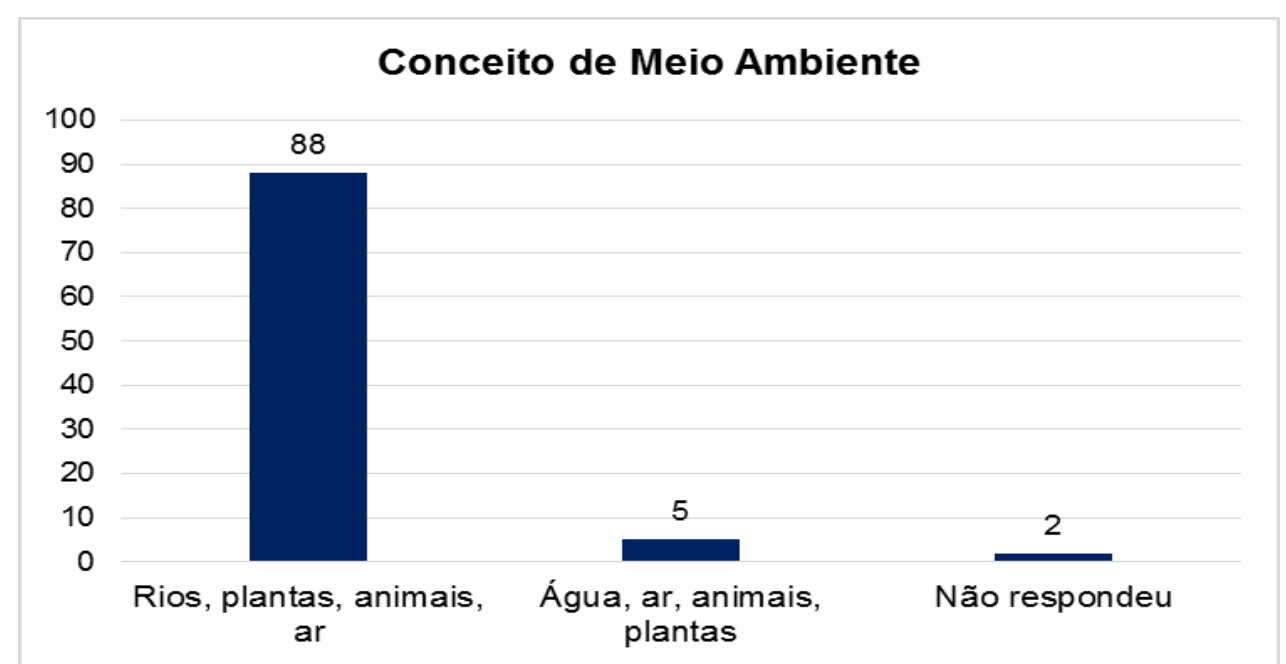

Figura 1: Gráfico referente ao conceito de Meio Ambiente

Fonte: autoria própria

E ainda 2\% não souberam responder ao questionamento, ofertando um campo fértil para intervenções que possam auxiliá-los na compreensão do conceito de meio ambiente, de forma que esse envolva todo o meio biofísico, social, cultural e econômico. 
Quanto ao questionamento sobre o conceito de Educação Ambiental, na figura 2 é possível verificar que $85 \%$ relacionam a reciclagem, coleta seletiva e semana do meio ambiente (Figura 2).

Outros 6\% acreditam que se trata Educação Ambiental através de atividades na semana da água e outras referentes ao cuidado com a limpeza do local.

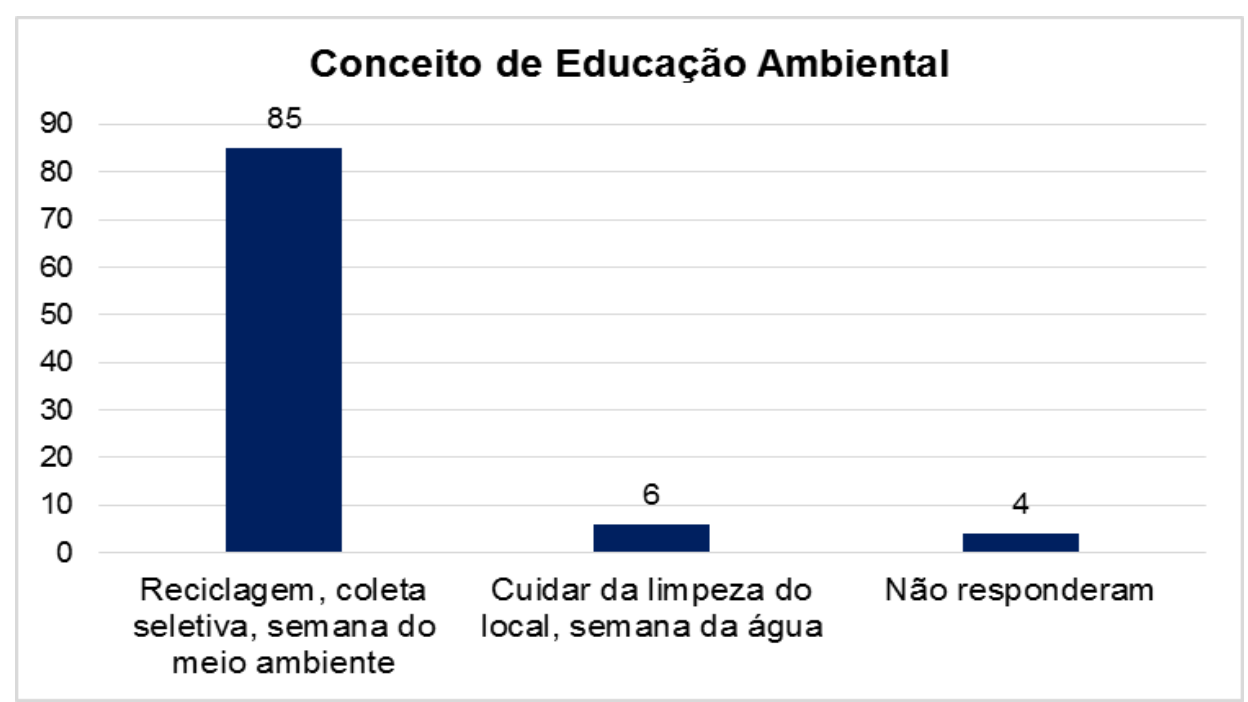

Figura 2: Gráfico relacionado ao conceito de Educação Ambiental

Fonte: Autoria própria

Dessa forma, é perceptível que $91 \%$ dos pesquisados confundem Educação Ambiental com a gestão ambiental. É possível que os profissionais que desenvolvem essas atividades na instituição sejam adeptos da corrente conservacionista de EA, que segundo Sauvé (2005, p.20), propõe atividades direcionadas à conservação dos recursos, tanto qualitativamente quanto quantitativamente, ou seja, é identificada a "natureza recurso", na qual existe o cuidado na conservação da água, dos animais, da energia, das plantas etc.

E ainda 4\% não responderam ao questionamento, sinalizando mais uma vez a necessidade de medidas interventivas que possam dirimir essa deficiência conceitual que pode ser a responsável por emular atitudes repetitivas, sem crítica ao atual modelo de consumo.

Pois afirma Reigota (2014, p. 13), que:

A Educação Ambiental como educação política está comprometida com a ampliação da cidadania, da liberdade, da autonomia e da intervenção direta dos cidadãos e cidadãs na busca de soluções e alternativas que permitam a convivência digna e voltada para o bem comum. 
E ainda nesse viés reflexivo a partir da compreensão desse contexto em que estão estacionados os pensamentos dos discentes, é precípuo que sejam emulados pensamentos reflexivos acerca da alienação em que esses jovens estão adentrando, quando demonstram alheios aos resultados de sua própria atividade (SILVA, 2014).

No próximo questionamento é possível verificar que na instituição de ensino pesquisada a Educação Ambiental é mais direcionada para a concepção conservadora, aquela em que a proteção ao ambiente ocorre pelo ser humano, sem, entretanto, discutir o porquê dessa atitude (SAUVÉ, 2005).

O ambiente é visto como um algo que deve ser cuidado, pois a natureza coisificada está impregnada nos conceitos desses sujeitos sociais, comprovados pelas respostas na Tabela 1.

Tabela 1: Na sua escola trabalham a EA? Explique como.

\begin{tabular}{|l|c|}
\hline Respostas dos discentes & $\%$ \\
\hline Sim. Semana do meio ambiente e dia da água & 37 \\
\hline $\begin{array}{l}\text { Sim. Trabalho sobre a coleta seletiva de garrafas pet para a } \\
\text { reciclagem, que será usada nos canteiros da horta. }\end{array}$ & 29 \\
\hline $\begin{array}{l}\text { Sim. Projeto sobre a limpeza da sala e da escola e também sobre a } \\
\text { água do planeta, na aula de Ciências. }\end{array}$ & 26 \\
\hline Não responderam & 8 \\
\hline
\end{tabular}

Fonte: Autoria própria

E são essas ações pontuais, diretamente vinculadas à gestão ambiental que muitas vezes inibe outros projetos sobre EA, pois segundo Guimarães (2011), a EA passa a ser reducionista, muitas vezes ingênua, pois não coloca em pauta de debate as causas que levaram a esse consumo excessivo que provoca a enorme quantidade de lixo para reciclagem, ou o desperdício de alimentos, água e energia, mas, sobretudo, o papel do ser humano enquanto agente transformador do meio em que vive.

Ainda pesquisando sobre a temática ambiental e sustentabilidade, foi questionado aos alunos o que eles entendiam por sustentabilidade, dos $100 \%$ pesquisados, um total de $91 \%$ não conseguiram expor seu conhecimento sobre sustentabilidade, deixando em branco a resposta e apenas $4 \%$ afirmaram ser proteção da natureza para a geração futura, simplificando a definição do Relatório de Brundtland.

É certo que conceituar sustentabilidade não é uma tarefa fácil, haja vista tantas discussões teóricas que se fazem atualmente acerca desse tema. Assim não é algo tão preocupante que alunos do nono ano não tenham um conceito formado de sustentabilidade (MALVEZZI, 2013). 
Entretanto, a EA crítica propõe a responsabilidade socioambiental, que está intrinsicamente ligada à sustentabilidade, pois ambas almejam uma melhor qualidade de vida para as populações locais, regionais e planetárias (LIMA, 2007).

Então, é pertinente realizar ações pontuais com esses indivíduos para que possam iniciar o processo reflexivo de ressignificação de conceitos, através da visão de pertencimento ao meio ambiente social, econômico, cultural, físico, para que possam realizar modificações nesses meios, de modo que melhore sua qualidade de vida e da comunidade local.

\section{A caminhada prática é sutil e enternecedora, quando a vontade é de todos}

Após a análise dos dados obtidos nos questionários, a preocupação primária da equipe foi apresentar ao discente o seu pertencimento à natureza, procurando refletir com ele acerca do fato de que todas as suas ações repercutem nos mais variados sistemas do planeta, como o físico, o biofísico, o social, cultural, histórico, econômico, políticos e que esses estão interligados (CAPRA, 2005).

Portanto, optou-se pelo uso de dinâmicas para demonstrar que o ser humano pertence à natureza, pois está sujeito a leis naturais assim como outros seres vivos e para estabelecer essa associação, foi escolhida a dinâmica lúdica, afirma Huizinga (1980), que o lúdico perpassa pela seriedade, pela oportunidade de vivenciar a realidade de outra forma, menos impactante, entretanto, sem ser leviana.

Assim, na primeira atividade, o aluno sentado em uma cadeira, tenta levantar-se sem modificar seu centro de força (Figura 3).

E ao perceber a impossibilidade do ato, também se percebe sujeito à força da gravidade, proporcionando a reflexão acerca das leis naturais que existem e às quais estão todos subjugados, pois pertencem a esses meios físicos e sociais (CAPRA, 1996).

No momento de reflexão, em forma de roda de conversa, muitos afirmaram surpresos ao serem apresentados a essas leis naturais e entre risos se encantaram com a descoberta. 


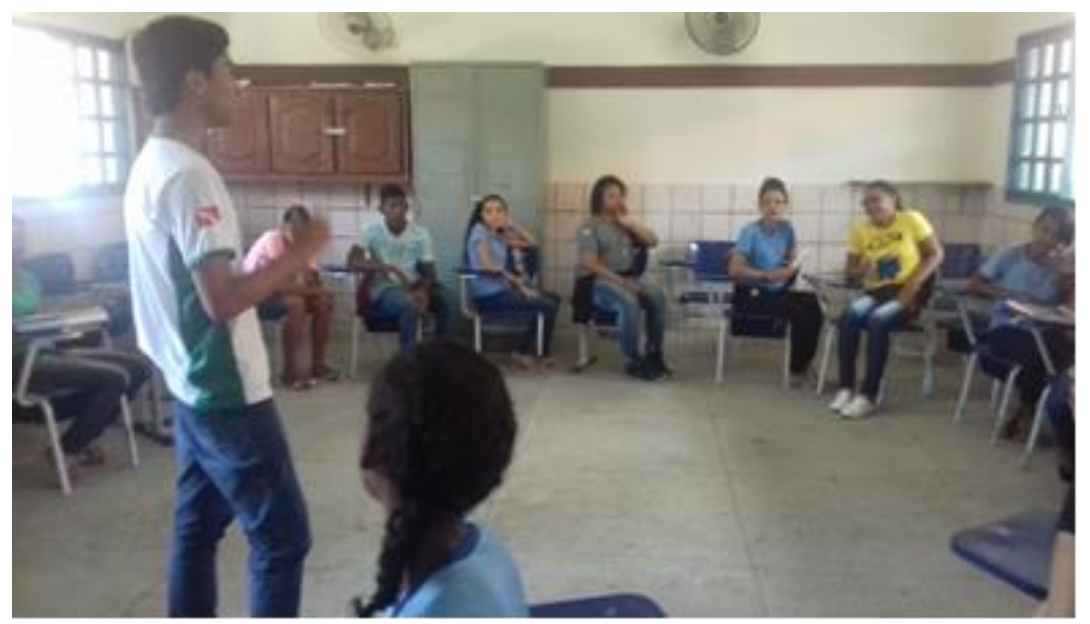

Figura 3: Dinâmica da gravidade

Fonte: Arquivo pessoal

$\mathrm{Na}$ segunda dinâmica relacionada ao impacto ao caminhar, os alunos tamparam seus ouvidos com as mãos e trilharam um caminho aleatório pela escola, de forma a perceberem as diferenças da topografia e da paisagem.

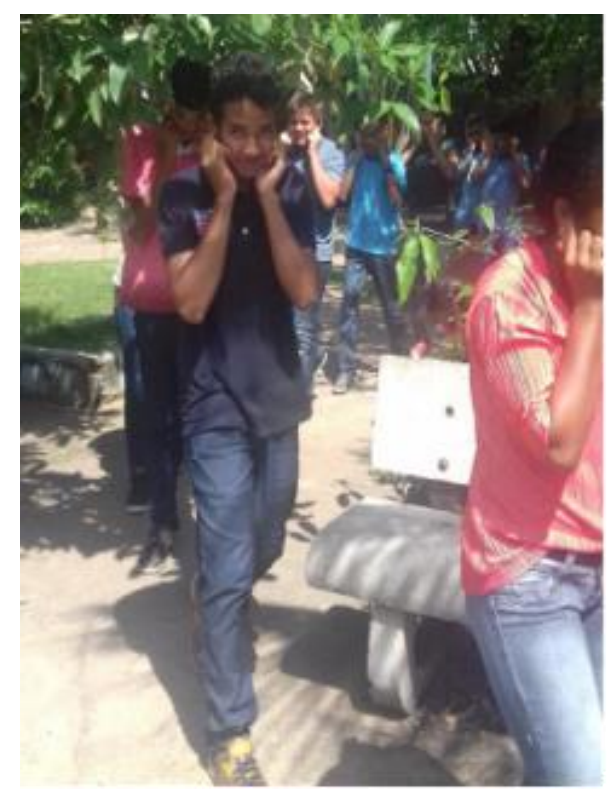

Figura 4: Dinâmica Impacto ao caminhar Fonte: Arquivo pessoal

A reflexão iniciou-se com os participantes apontando como foi desagradável ouvir daquela maneira, oportunizando a reflexão acerca da desvalorização do corpo humano através do uso de drogas lícitas e/ou ilícitas, da alimentação inadequada, do uso incorreto de aparelhos como telefones celulares, notebooks, televisão, que podem danificar a visão e audição. Também foi relacionado ao ato de caminhar, em como utilizamos princípios físicos para caminhar e não nos apercebemos, pois estamos automatizados. 
E essa automatização influencia o comportamento do ser humano, que se torna massificado, homogeneizando os pensamentos e dificultando as reflexões críticas acerca das atitudes cotidianas, sendo que essas formas de comportamento são impostas por um modelo econômico que, atualmente, percebe-se está em contramão com a sustentabilidade socioeconômica, pois é predatório, consumista e individualista (CARVALHO, 2016).

$\mathrm{Na}$ terceira dinâmica, sentindo a natureza em mim, os alunos foram divididos em pares e um dos participantes foi vendado, tendo que depender do parceiro para caminhar por uma trilha na área verde da escola. Os objetivos eram verificar o nível confiabilidade entre os pares que realizariam a atividade, além de que os participantes que estivessem privados da visão pudessem se sentir enquanto natureza, observando como o corpo reage diante de situações inusitadas.

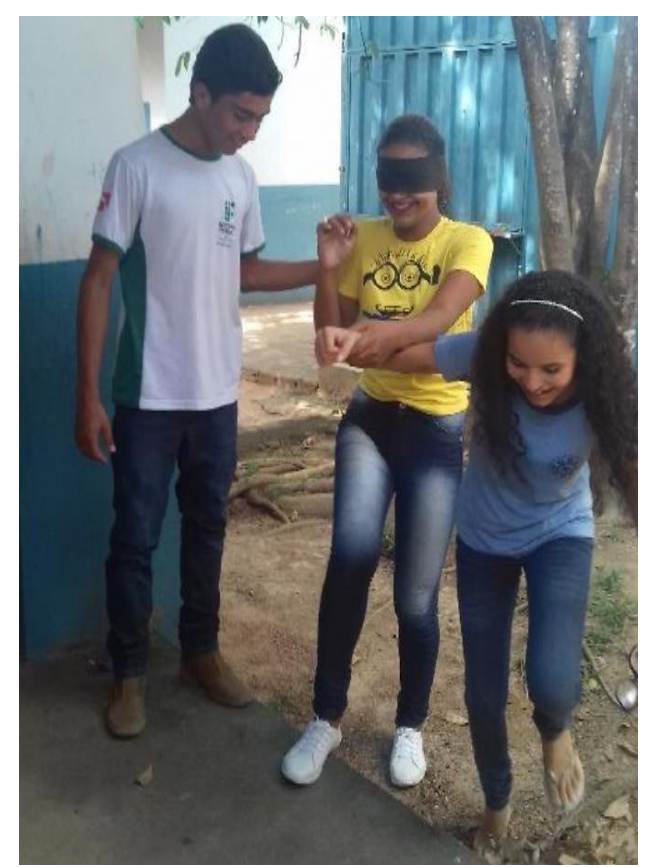

Figura 5: Dinâmica Sentindo a natureza em mim

Fonte: Arquivo pessoal

Nesse momento, reportamos a Huisinga (1980, p. 13), “(...) em uma situação excepcional, de partilhar algo importante, afastando-se do resto do mundo e recusando as normas habituais, conserva sua magia", e foi interessante verificar as reações dos discentes diante dessa dinâmica, iniciando pela falta de confiança no parceiro e em si mesmo quando privado do sentido da visão. Entre risos afirmaram que ouviram o coração disparado, uns sentiam solidão, outros tristeza, outros medo de cair, de não voltar a enxergar.

E diante da reflexão iniciada foi trabalhada a sustentabilidade pessoal através da valorização do corpo humano, da necessidade de cuidar-se e de respeitar as limitações e potencialidades do outro, haja vista as diferenças que existem entre os seres humanos, por isso todos dependem uns dos outros. 
Esse foi um momento em que a sustentabilidade em seus três pilares: social, ambiental e econômico foi bastante debatida, principalmente a nível local, pois os adolescentes fizeram apartes que identificavam suas vivências na comunidade e de como essa comunidade o afetava, mas principalmente o que eles poderiam fazer para modificar positivamente seu ambiente, tanto biofísico, quanto socioeconômico.

O intuito nesses diálogos era que pudessem perceber como pertencentes à natureza, portanto são atores sociais, que podem e devem exercer a cidadania, com ética e responsabilidade (CARVALHO, 2016).

Já na quarta dinâmica, intitulada Dinâmica dos Sistemas, foram divididos em dois grupos, a um grupo foi repassado o comando de que deveriam escolher duas pessoas e o aluno deveria ficar equidistante dos dois escolhidos, e sempre que um se movesse, deveria mover-se mantendo a equidistância e cada um segurando um cartaz com uma frase ou vocábulo relacionado ao tema ambiental e social: água, flora, fauna, relações sociais etc.

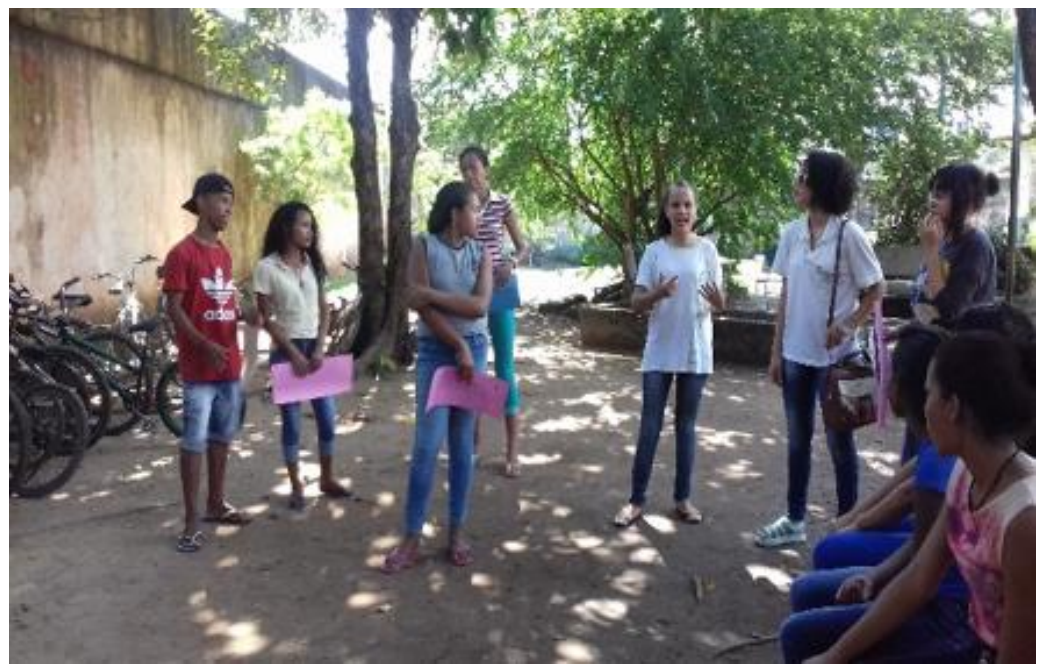

Figura 6: Dinâmica dos Sistemas

Fonte: Arquivo pessoal

Ao segundo grupo foi pedido que observassem o primeiro grupo e descobrissem qual o comando repassado. A dinâmica prosseguiu durante tempo suficiente para que os participantes do grupo 2 sugerissem alguns comandos. Ao término, foi possível discutir com os discentes sobre essas interrelações que existem entre os seres humanos e entre os fatores econômicos, sociais, culturais, históricos, políticos e ambientais.

Nos momentos reflexivos os discentes teceram considerações importantes acerca da responsabilidade que recai sobre cada um, tanto em relação ao consumismo que é ditado pelas propagandas afeitas ao modelo capitalista vigente, quanto à quantidade e qualidade do lixo produzido, além da responsabilidade em trabalhar as questões de relacionamento social, ou seja, evidenciar o respeito pelas diferenças. 
Para encerrar o momento de intervenções foi aplicada a ficha avaliativa para que os discentes pudessem avaliar seu nível de entendimento das questões discutidas e também o desenvolvimento da atividade pelos alunos do Cmpus Marabá Industrial.

Pois segundo Luckesi (1995), a avaliação dentro do processo de criação, desenvolvimento de um projeto, ou plano de ação deve primar pela criticidade, como um instrumento dialético para diagnosticar o desenvolvimento dos grupos estudados, de modo a auxiliar na transformação social do mesmo, através da definição ou redefinição de diretrizes educacionais.

Assim, essa ficha avaliativa foi composta de duas partes: na primeira foram elencados 10 itens que relacionavam o ambiente físico para as dinâmicas, a condução das mesmas, o aprendizado, para serem avaliados com os conceitos insuficiente, regular, bom, excelente.

$\mathrm{Na}$ outra parte foram apresentadas três carinhas de smiles com as referências: Que bom, que pena e que tal? Visando sugestões dos discentes para as próximas ações.

E na tabulação dessas informações verificou-se que a maioria avaliou de bom a excelente os locais, a condução das dinâmicas, o aprendizado e nas sugestões foi percebido que todos acenaram que bom o IFPA, na presença dos discentes e docentes terem ofertado a oficina, também avaliaram que o tempo foi curto e que nas próximas atividades mais professores e alunos pudessem participar.

Em relação aos professores da instituição foi gratificante o trabalho em conjunto com os mesmos, pois receberam o grupo com gentileza, ajudaram no sentido de pedirem a colaboração dos alunos e também solicitaram a parceria com a escola em outros momentos, auxiliando-os em seus trabalhos relativos à temática Meio Ambiente.

\section{Considerações finais}

Trabalhar a Educação Ambiental crítica e emancipatória é pertinente, quando percebe que pode proporcionar situações propícias ao indivíduo modificar o seu olhar sobre o seu ambiente de estudo, de trabalho, de descanso ou socialização.

Esse modo de perceber o mundo é que fará dos indivíduos sujeitos críticos, com informações e reflexões e conseguirão realizar as modificações positivas que almejam de forma a uma melhor qualidade de vida, tanto a nível econômico, social, cultural, quanto ambiental, no sentido de natureza física.

E durante a realização dessa pesquisa participante ocorreu um grande aprendizado para os discentes e docentes da escola municipal Salomé de Carvalho, quanto para a equipe de docentes e discentes do Campus Marabá Industrial, pois a aprendizagem é constante e possível.

Portanto, os resultados contemplados com a técnica de dinâmicas lúdicas podem ser descritos como positivos e recompensadores, pois mobilizou Revbea, São Paulo, V. 12, № 5: 84-98, 2017. 
alunos adolescentes de duas instituições diferentes em um ambiente para reflexões sérias e urgentes, utilizando uma linguagem jovem, respeitando diferentes pensamentos, sendo um dos objetivos da Educação Ambiental crítica e emancipatória.

Utilizar o lúdico para apresentar a esses alunos seu pertencimento à natureza foi significante, haja vista que temas sérios e muitas vezes difíceis de serem trabalhados foram tratados com leveza e a participação dos alunos foi total, porquanto em todas as dinâmicas realizadas ocorreram sorrisos e vontade de continuar o momento.

Ao trabalhar o pertencimento à natureza é apenas o primeiro passo para desbravar todo o universo de conceitos que abrange a Educação Ambiental crítica e emancipatória e sustentabilidade, visando uma ressignificação desses, evoluindo para mudança de atitudes e comportamentos que abarquem os pilares sociais, econômicos e políticos da sociedade.

Desde o primeiro momento em que foi apresentada a proposta à instituição Salomé de Carvalho, através dos gestores e corpo docente esse trabalho foi bem recebido e ansiado, pois existe a carência de atividades que envolvam os adolescentes e jovens para a reflexão de temas atuais, principalmente de forma que eles sintam vontade de participar e que possa concorrer com toda a tecnologia que invade suas vidas.

Quanto à participação dos alunos, ainda pode-se elencar que desde o momento da recepção até o último instante foi percebido a alegria e a boa vontade em cooperar com a equipe na realização do trabalho. Mesmo com a timidez inicial, natural em um grupo de adolescentes, que estavam lidando com outros adolescentes e de outra escola, foi muito produtivo, os mesmos cooperaram no sentido de participarem nas discussões, apresentando suas opiniões sem medo de errarem, apenas contribuindo com o desenrolar da atividade.

Em todas as dinâmicas ocorreram descobertas, foi possível realizar correlações às quais os participantes se manifestaram surpresos com a sua própria falta de percepção das leis da natureza, como a da gravidade, e também, em suas falas, ficou perceptível que compreenderam o seu pertencimento à natureza.

É claro que não espera, que apenas esses momentos possam modificar completamente a maneira de pensar e agir desses adolescentes, entretanto, é pertinente afirmar que as informações repassadas através das dinâmicas lúdicas tiveram um impacto positivo emotivaram um comportamento reflexivo nos alunos, que é um grande passo nesse caminho de emancipação crítica do ser humano. 


\section{Referências}

BRASIL. Lei № 9.795 de 27 de abril de 1999. Política Nacional de Educação Ambiental. Brasília: 1999.

BRASIL. Lei № 6.938 de 31 de agosto de 1981. Política Nacional do Meio Ambiente. Brasília: 1981.

CANDAU, V. Currículo, Didática e Formação de Professores: uma teia de ideias, força e perspectivas de futuro. In: PACHECO, J. A.; OLIVEIRA, M. R. N.S. (Org.) Currículo, didática e formação de professores. Campinas, SP: Papirus, 2013.

CAPRA, F. Alfabetização ecológica: o desafio para a educação do século XXI. In: Meio ambiente no século XXI. $4^{a}$ ed. Campinas, SP: Armazém do Ipê, 2005.

CAPRA, F. A Teia da Vida. São Paulo: Editora Cultrix, 1996.

CARVALHO, I.C.M. Educação Ambiental: a formação do sujeito ecológico. $6^{\mathbf{a}}$ ed. São Paulo: Cortez, 2016.

DIAS, G.F. Dinâmicas e Instrumentação para a Educação Ambiental. São Paulo: Gaia, 2013.

FREIRE, P. Pedagogia da autonomia: saberes necessários à prática educativa. 25aㅡ ed. São Paulo: Editora Paz e Terra, 1996.

GUIMARÃES, M. Armadilha paradigmática na Educação Ambiental. In: LOUREIRO, C. F. B. (Org). Pensamento complexo, dialética e Educação Ambiental. 2 ${ }^{\mathrm{a}}$ ed. São Paulo: Cortez, 2011.

HUIZINGA, J. Homo ludens: o jogo como elemento da cultura. São Paulo: Perspectiva, 1980.

LIMA, G. Ferreira da Costa. Responsabilidade socioambiental e sustentabilidade. In: JUNIOR FERRARO, L. A. (Org.). Encontros e Caminhos: formação de educadoras (es) ambientais e coletivos educadores. Brasília: MMA, 2007.

LUCKESI, C. Avaliação e Aprendizagem escolar. São Paulo: Cortez, 1995.

MALVEZZI, M. Sustentabilidade e emancipação: a gestão de pessoas na atualidade. São Paulo: Editora Senac São Paulo, 2013.

REIGOTA, M. O que é Educação Ambiental. São Paulo: Brasiliense, 2014.

SAUVÉ, L. Uma cartografia das correntes em Educação Ambiental. In: SATO, M.; CARVALHO, I.C.M. (Coord.). Educação Ambiental: pesquisas e desafios. Porto Alegre: Artmed, 2005.

SILVA, L.F. Educação Ambiental crítica: entre ecoar e recriar. Jundiaí, SP:

Paco Editorial, 2014. 